\title{
A Blue Leg: An Interventional Approach to a Limb-Threatening Deep Vein Thrombosis
}

By Andrea Cervi MD; Lisa Kim MD; Sriharsha Athreya MD, FRCS, FRCR; Jason Cheung MD, FRCPC

\begin{abstract}
About the Authors:
Dr. Andrea Cervi and Dr. Lisa Kim are PGY-3 Internal Medicine residents with the Department of Medicine, McMaster University. Dr. Sriharsha Athreya is an interventional radiologist at St. Joseph's Healthcare Hamilton. He is an Associate Professor with the Department of Radiology, McMaster University. Dr. Jason Cheung is an academic internist based primarily at St. Joseph's Healthcare Hamilton. He is an Assistant Professor with the Division of General Internal Medicine, Department of Medicine, McMaster University. Correspondence may be directed to: andrea.cervi@medportal.ca
\end{abstract}

\begin{abstract}
Phlegmasia cerulea dolens (PCD) is a rare complication of acute deep vein thrombosis (DVT) characterized by fulminant venous thrombosis that compromises arterial blood flow, resulting in tissue ischemia, venous gangrene, and possible loss of limb. A high rate of morbidity and mortality associated with PCD requires prompt recognition and treatment. An accepted therapeutic algorithm for the management of PCD does not currently exist. Acute reduction in clot burden can be achieved through catheter-directed thrombolysis (CDT) with lower rates of post-thrombotic symptoms, and there has been a recent trend toward use of CDT. We report the case of a 26-year-old female who presented with PCD of her left leg and underwent successful CDT, highlighting the benefits of rapid recognition of a rare complication of acute DVT, and the role for a multidisciplinary endovascular approach to managing fulminant limbthreatening venous thrombosis.

La phlegmatia caerulea dolens (PCD) est une complication rare de la thrombose veineuse profonde (TVP) aiguë caractérisée par une thrombose veineuse foudroyante qui compromet le débit sanguin et résulte en une ischémie tissulaire, une évolution vers la gangrène et le risque de perte de membre. La PCD est associée à un taux élevé de morbidité et de mortalité et requiert une reconnaissance et un traitement rapides. Il n'existe actuellement pas de modèle défini d'intervention pour la prise en charge de la PCD. Une réduction rapide du caillot peut être obtenue par thrombolyse guidée par cathéter (TGC), intervention associée à un taux plus faible de symptômes post-thrombotiques. Le recours à la TGC est d'ailleurs plus fréquent depuis peu. Nous décrivons ici le cas d'une patiente âgée de 26 ans qui présentait une PCD à la jambe gauche et qui a été traitée avec succès par TGC. Ce cas fait ressortir l'importance de savoir reconnaître rapidement une complication rare de la TVP aiguë, ainsi que d’appliquer une approche endovasculaire multidisciplinaire dans la prise en charge d'une thrombose veineuse fulminante susceptible de causer la perte d'un membre.
\end{abstract}


Phlegmasia cerulea dolens (PCD) is a rare manifestation of acute proximal deep vein thrombosis (DVT) in which extensive clot causes arterial insufficiency and compartment compression. ${ }^{1}$ This can result in venous gangrene, threatening limb viability, and requires acute intervention. Catheter-directed thrombolysis (CDT) entails selective infusion of a thrombolytic agent at the site of thrombus via a penetrating catheter under radiographic guidance. This approach is a viable therapeutic option in the management of PCD as it can rapidly restore limb perfusion while minimizing systemic bleeding complications.

Clinical practice guidelines directing the use of CDT for treatment of lower limb DVTs are varied. The most recent 2016 American College of Chest Physicians' guidelines provide a weak recommendation for $\mathrm{CDT}$ in carefully selected patients, ${ }^{2}$ whereas the Society of Interventional Radiology strongly advises consideration of CDT in patients with extensive iliofemoral DVT. ${ }^{3}$ Limited trial data has highlighted the efficacy of CDT in optimizing venous patency and mitigating the incidence of chronic DVT complications, namely post-thrombotic syndrome (PTS) and venous ulceration, in acute iliofemoral DVT. ${ }^{4-7}$ The immediate thromboreduction afforded by CDT may minimize the chronic venous remodeling that results from the presence of residual clot which underlies the pathophysiology of PTS. A full appreciation of the immediate and long-term complications of CDT is lacking, thus creating controversy surrounding its use. ${ }^{8}$ We report a case of PCD that was successfully treated with CDT, highlighting the need for rapid recognition of a rare complication of an acute DVT and the benefit of CDT in carefully selected patients.

\section{CASE DESCRIPTION}

A 26-year-old female presented to the Emergency Department (ED) at one of our tertiary care, academic hospitals with an 8-hour history of acute-onset, non-resolving left leg pain, swelling, and discoloration. The patient had also been experiencing exertional dyspnea and gradually worsening pleuritic chest pain for the past 1.5 weeks. Thromboembolic risk factors included obesity and use of the oral contraceptive pill. There was no history of previous venous thromboembolism, autoimmune disease, pregnancy loss, or malignancy. Family history was positive for postpartum pulmonary embolism in the patient's mother.

The patient was hemodynamically stable in the ED although with a slightly elevated heart rate of $93 \mathrm{bpm}$ on arrival at triage. Her physical examination revealed a left leg that was markedly edematous from proximal thigh to foot, with accompanying blue discoloration, and significant pain to palpation of her limb. The range of motion was limited due to pain. Although the leg's neurovascular status was intact, distal pulses were weak and the leg was cooler compared to the other. A computed tomography pulmonary angiogram confirmed the presence of multiple large, acute pulmonary emboli in the interlobar, lobar, and segmental arteries bilaterally with associated lung infarcts and leftward bowing of the interventricular septum, suggestive of right heart strain. Doppler ultrasound of the patient's leg revealed extensive occlusive thrombus extending distally from the left external iliac vein to the trifurcation (Figure 1). Weight-based low molecular weight heparin was initiated; however, given the extensive burden of clot, consultations with both the Hematologist and Interventional Radiologist led to the decision of pursuing CDT. Prior to initiation of CDT, an IVC filter was inserted given the extent of the patient's pulmonary emboli.

Using ultrasound guidance, the extensive thrombus was pulse sprayed with tissue plasminogen activator (TPA) using an AngioJet device (Figure 2), followed by mechanical thrombectomy and balloon angioplasty of the external iliac vein. TPA and heparin infusions were continued at the site of the thrombus in conjunction with systemic anticoagulation using a heparin infusion protocol. Follow-up venogram 24 hours later demonstrated patency of the left superficial and common femoral veins with residual non-occlusive thrombus in the left common iliac vein, at which time the selective infusions of TPA and heparin were discontinued. The patient tolerated the procedure well with no complications and was discharged home on rivaroxaban four days later. She continues to do well with minimal symptoms of PTS after 1 year follow-up

\section{DISCUSSION}

Clinical features that have been shown to optimize the success of endovascular therapy for DVTs include acute onset of symptoms, often within 14 days, iliofemoral location of clot,
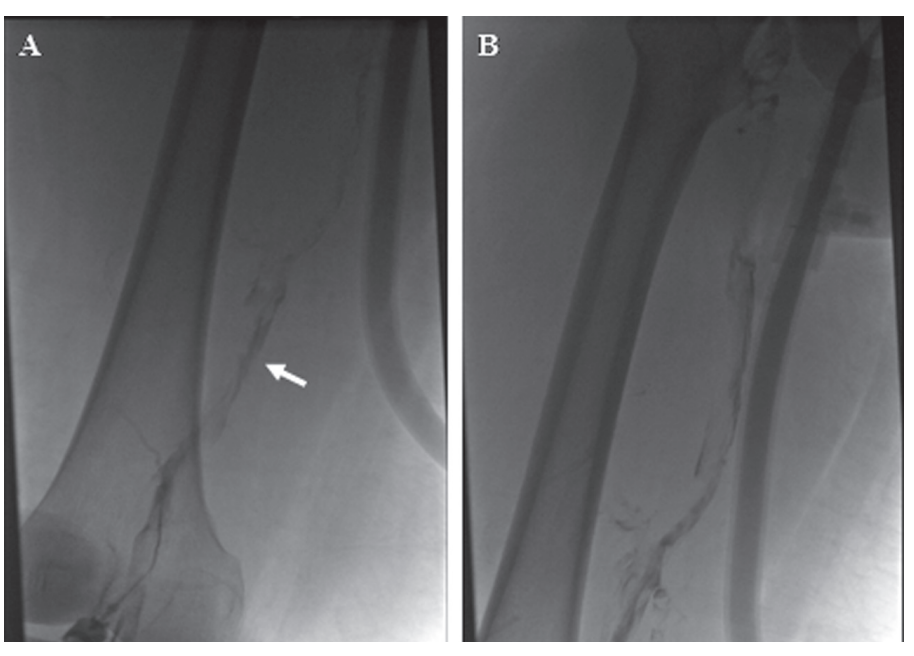

Figure 1. Venogram of left femoral vein (white arrow) demonstrating extensive thrombus (A). Proximal view of thrombus in left external iliac vein (B). 



Figure 2. Venograms during and 24 hours post-CDT. Angio Jet device in situ, with inferior catheter site holes for TPA release (A). Balloon angioplasty of stenosis in left external iliac vein (B). Venogram post-CDT, demonstrating patency in the left femoral and external iliac veins (C).

and low risk bleeding profile, ${ }^{2}$ all of which were present in our patient and likely contributed to her favourable outcome. Moreover, our patient had extensive, flow-limiting thrombus on Doppler ultrasound that was clinically manifest as widespread limb edema, acute ischemic pain, and discoloration, consistent with a diagnosis of PCD. Rapid recognition of PCD is required to institute venous recanalization and salvage limb viability. Guidelines for the management of this scenario are currently lacking but there has been a recent trend toward use of more aggressive techniques such as $\mathrm{CDT}^{8,9}$ Ongoing multicentre trials (ATTRACT, DUTCHCAVA) will help to inform future decision-making regarding the possibility of broadening the use of endovascular therapy for management of acute DVT, ${ }^{10}$ as it currently remains highly individualized and centre-specific.

Ultimately, this case illustrates the role for a multidisciplinary approach to the management of a limb-threatening DVT. Recognition of PCD and rapid referral to a centre that is capable of performing an interventional radiological procedure may help to prevent significant morbidity.

\section{REFERENCES}

1. Chinsakchai K, Duis T, Moll FL, et al. Trends in management of phlegmasia cerulea dolens. Vasc Endovascular Surg 2011;45(1):5-14.

2. Kearon C, Akl EA, Ornelas J, et al. Antithrombotic therapy for VTE disease: CHEST guideline and expert panel report. Chest 2016;149(2):315-52.
3. Vedantham S, Millward SF, Cardella JF, et al. Society of Interventional Radiology position statement: treatment of acute iliofemoral deep vein thrombosis with use of adjunctive catheter-directed intrathrombus thrombolysis. J Vasc Interv Radiol 2006;17:613-16.

4. Elsharawy $\mathrm{M}$ and Elzayat E. Early results of thrombolysis vs. anticoagulation in iliofemoral venous thrombosis. A randomised clinical trial. Eur J Vasc Endovasc Surg 2002;24(3):209-14.

5. Enden T, Klow NE, Sandvik L, et al. Catheter-directed thrombolysis vs. anticoagulant therapy alone in deep vein thrombosis: results of an open randomized, controlled trial reporting on short-term patency. J Thromb Haemost 2009;7(8):1268-75.

6. Enden T, Haig Y, Klow NE, et al. Long-term outcome after additional catheter-directed thrombolysis versus standard treatment for acute iliofemoral deep vein thrombosis (the CaVenT study): a randomised controlled trial. Lancet 2012;379(9810):31-38.

7. Haig Y, Enden T, Grotta O, et al. Post-thrombotic syndrome after catheterdirected thrombolysis for deep vein thrombosis (CaVenT): 5-year follow-up results of an open-label, randomised controlled trial. Lancet Haematol 2016;3(2):e64-71.

8. Bashir R, Zack CJ, Zhao H, et al. Comparative outcomes of catheterdirected thrombolysis plus anticoagulation vs. anticoagulation alone to treat lower-extremity proximal deep vein thrombosis. JAMA Intern Med 2014;174(9):1494-501.

9. Watson L, Broderick C, Armon MP. Thrombolysis for acute deep vein thrombosis. Cochrane Data Syst Rev 2014;1, Art. No.: CD002783.

10. Liew A and Douketis J. Catheter-directed thrombolysis for extensive iliofemoral deep vein thrombosis: review of literature and ongoing trials. Expert Rev Cardiovasc Ther 2016;14(2):189-200. 